\title{
MENGKLASIFIKASIKAN DESA PERKOTAAN DAN DESA PERDESAAN DI KABUPATEN KLUNGKUNG MENGGUNAKAN METODE MAMDANI
}

\author{
Ni Kadek Sumarwati ${ }^{1 \S}$, G. K. Gandhiadi ${ }^{2}$, Tjokorda Bagus Oka ${ }^{3}$ \\ ${ }^{1}$ Program Studi Matematika, Fakultas MIPA - Universitas Udayana [Email: kdsumar@gmail.com] \\ ${ }^{2}$ Program Studi Matematika, Fakultas MIPA - Universitas Udayana [Email: gandhiadi@unud.ac.id] \\ ${ }^{3}$ Program Studi Matematika, Fakultas MIPA - Universitas Udayana [Email: tjokordabagusoka@gmail.com] \\ ${ }^{\S}$ Corresponding Author
}

\begin{abstract}
According to Bureau of Statistic, village can be classified into urban and rural village. This classification is useful for planning development, such as security, health, and agriculture plans which have the roles of rural urban linkages. This classification also useful for divide a village into villages. In this research the villages in Klungkung Regency will be classified into urban and rural villages using Mamdani method. The result of classification using Mamdani method is 52 villages classified into urban village and seven villages classified into rural village which has an accuracy of 93\% between the Mamdani method output with the original data in 59 villages in Klungkung Regency.
\end{abstract}

Keywords: fuzzy logic, Mamdani method, classification, urban, rural, accuracy

\section{PENDAHULUAN}

Kabupaten Klungkung merupakan kabupaten yang luasnya terkecil kedua setelah Kota Denpasar dari sembilan kabupaten dan kota di Bali dengan luas wilayah $315 \mathrm{~km}^{2}$ (Badan Pusat Statistik Kabupaten Klungkung, 2016). Secara administratif Kabupaten Klungkung terdiri dari empat kecamatan dan 59 desa/kelurahan. Setiap desa mempunyai ciri dan tipologi lingkungan, kondisi ekonomi, akses fasilitas umum yang berbeda-beda, dan akan terus berubah seiring dengan kemajuan tingkat pembangunan di suatu desa. Berdasarkan peraturan Kepala Badan Pusat Statistik Nomor 37 Tahun 2010 tentang klasifikasi perkotaan dan perdesaan di Indonesia maka desa/kelurahan dapat dikategorikan menjadi wilayah perkotaan dan wilayah perdesaan berdasarkan nilai/skor dari indikator yang telah ditetapkan oleh Badan Pusat Statistik. Indikator yang dimaksud adalah kepadatan penduduk (jiwa/ $/ \mathrm{km}^{2}$ ), persentase rumah tangga pertanian (\%), dan akses fasilitas umum (Badan Pusat Statistik, 2010).
Skor atau nilai dalam klasifikasi ditentukan dengan batas minimal 10 maka desa tersebut termasuk perkotaan sedangkan apabila skor kurang dari 10 maka desa berstatus perdesaan (Badan Pusat Statistik, 2010). Adanya perubahan kecil nilai pada suatu indikator mengakibatkan perbedaan skor yang dapat mengubah status suatu desa. Hal tersebut sangat kaku, sehingga himpunan fuzzy akan digunakan dalam penelitian ini yang dirasa mampu untuk mengantisipasi hal tersebut. Salah satu metode yang dapat digunakan dalam pengaplikasian logika fuzzy untuk mengklasifikasikan desa perkotaan dan desa perdesaan adalah metode Mamdani.

Metode Mamdani pertama kali diperkenalkan oleh Ebrahim Mamdani pada tahun 1975. Metode Mamdani juga sering disebut metode Min-Max, yaitu mencari nilai minimum dari setiap aturan dan nilai maksimum dari gabungan konsekuensi setiap aturan (Kusumadewi \& Purnomo, 2010). Metode 
Mamdani memiliki kelebihan yakni, lebih intuitif, diterima oleh banyak pihak, cocok digunakan apabila input diterima dari manusia bukan mesin.

Beberapa penelitian tentang logika fuzzy metode Mamdani yaitu penelitian oleh Ayuningtiyas, dkk. (2007) yang memperoleh hasil akurat dalam pengambilan keputusan mengenai keadaan balita di suatu daerah, penelitian oleh Arifin, dkk. (2015) yang bertujuan untuk mendeteksi kerentanan banjir di Semarang Utara menggunakan lima defuzifikasi memperoleh hasil pengujian dengan kesimpulan yang sama dari dua contoh kasus, dan penelitian oleh Muthohar, dkk. (2016) yang bertujuan untuk mengevaluasi kinerja pelayanan perawat berdasarkan tangibility, reliability, responsiveness, assurance, dan empathy memperoleh hasil yang sesuai antara keluaran sistem fuzzy dengan keluaran yang diharapkan.

Pada penelitian ini logika fuzzy metode Mamdani digunakan dalam mengklasifikasikan desa perkotaan dan desa perdesaan di Kabupaten Klungkung. Tujuan klasifikasi ini adalah untuk mengetahui klasifikasi dan ketepatan hasil klasifikasi desa perkotaan dan desa perdesaan di Kabupaten Klungkung menggunakan metode Mamdani.

\section{METODE PENELITIAN}

Data yang digunakan dalam penelitian ini adalah data sekunder yang diperoleh dari Badan Pusat Statistik Kabupaten Klungkung. Data tersebut merupakan data hasil pencatatan setiap kecamatan dan desa di Kabupaten Klungkung tahun 2016. Langkah-langkah yang dilakukan dalam penelitian ini adalah sebagai berikut:

1. Menentukan variabel input dan variabel output

Pada penelitian ini terdapat tiga variabel input yaitu Kepadatan Penduduk (KPD), Persentase Rumah Tangga Pertanian (PRT), dan Akses Fasilitas Umum (AFU) dan satu variabel output yaitu Status Desa (SD).

2. Menentukan himpunan universal dan himpunan fuzzy
Himpunan universal untuk variabel input yaitu: $\mathrm{KPD}=[0,20000], \quad \mathrm{PRT}=[0,100]$, dan $\mathrm{AFU}=[0,10]$ serta variabel output Status Desa $=[0,20]$. Sedangkan himpunan fuzzy untuk masing-masing variabel input akan dibagi menjadi tiga himpunan fuzzy dan dua himpunan fuzzy untuk variabel output. Nilai himpunan universal untuk variabel input dan output ditentukan oleh peneliti berdasarkan nilai minimum, maksimum, dan median data klasifikasi desa.

3. Menentukan aturan fuzzy

Banyaknya aturan fuzzy yang dapat terbentuk diperoleh dari hasil kali jumlah masing-masing himpunan fuzzy pada variabel input (Bojadziev \& Bojadziev, 2007).

\section{Aplikasi fungsi implikasi Min}

Pada langkah ini akan dicari output untuk setiap aturan dengan menggunakan fungsi implikasi min pada persamaan (1).

$\mu_{\alpha \wedge \mu_{\tilde{C}}}(z)=\alpha \wedge \mu_{\tilde{C}}(z)=\min \left(\mu_{\alpha}(z)=\right.$ $\left.\alpha, \mu_{\tilde{C}}(z)\right)$

dengan,

$$
\begin{gathered}
\alpha=\mu_{\tilde{A}}(x) \wedge \mu_{\tilde{B}}(y)=\min \left(\mu_{\tilde{A}}(x), \mu_{\tilde{B}}(y)\right) ; \\
x=x_{0} \text { dan } y=y_{0}
\end{gathered}
$$

Keterangan:

$\mu_{\alpha \wedge \mu_{\tilde{C}}}(z)=$ daerah hasil fungsi implikasi min $\alpha=$ nilai keanggotaan hasil operasi himpunan fuzzy $\tilde{A}$ dan $\tilde{B}$

$\mu_{\tilde{A}}(x)=$ derajat keanggotaan himpunan fuzzy $\tilde{A}$ $\mu_{\tilde{B}}(y)=$ derajat keanggotaan himpunan fuzzy $\tilde{B}$ $\mu_{\tilde{C}}(z)=$ derajat keanggotaan konsekuen pada himpunan $\tilde{C}$

\section{Melakukan agregasi}

Agregasi metode max akan digunakan dalam penelitian ini yaitu dengan mengambil nilai maksimum untuk setiap output himpunan fuzzy dari hasil aplikasi fungsi implikasi menggunakan persamaan (2) :

$\mu_{s f}\left(x_{i}\right)=\max \left(\mu_{s f}\left(x_{i}\right), \mu_{k f}\left(x_{i}\right)\right)$

dengan $\mu_{s f}\left(x_{i}\right)$ adalah nilai keanggotaan solusi fuzzy sampai aturan ke-i dan $\mu_{k f}\left(x_{i}\right)=$ nilai keanggotaan konsekuen aturan ke-i. 
6. Melakukan defuzzifikasi

Defuzzifikasi pada penelitian ini menggunakan metode centroid untuk mendapatkan nilai variabel solusi dari suatu daerah konsekuen dengan cara mengambil titik pusat daerah fuzzy menggunakan persamaan:

$z^{*}=\frac{\int_{z} z \mu(z) d z}{\int_{z} \mu(z) d z}$

\section{Keterangan:}

$z^{*}=$ nilai hasil penegasan (defuzzifikasi)

$Z \quad=$ nilai domain ke-j

$\mu(z)=$ derajat keanggotaan $\mathrm{z}$

\section{Hasil klasifikasi setiap desa}

Hasil klasifikasi setiap desa diperoleh dengan mensubstitusikan nilai defuzzifikasi ke dalam fungsi keanggotaan pada masing-masing himpunan fuzzy variabel output dan menentukan klasifikasi dari nilai yang diperoleh.

8. Uji ketepatan hasil klasifikasi

Pada langkah terakhir akan dihitung ketepatan hasil klasifikasi dengan menggunakan confusion matrix untuk membandingkan hasil klasifikasi metode Mamdani dengan data asli.

\section{HASIL DAN PEMBAHASAN}

Berikut adalah perancangan himpunan fuzzy untuk menentukan status desa.

Tabel 1. Tabel Himpunan Fuzzy

\begin{tabular}{|c|c|c|c|}
\hline Variabel & Himpunan & Domain & $\begin{array}{l}\text { Fungsi } \\
\text { Keanggotaan }\end{array}$ \\
\hline \multirow{3}{*}{ KPD } & Sedikit & {$[0,7176)$} & Bahu Kiri \\
\hline & Sedang & $\begin{array}{l}(80, \\
14271)\end{array}$ & Segitiga \\
\hline & Padat & $\begin{array}{l}(7176 \\
20000]\end{array}$ & Bahu Kanan \\
\hline \multirow{3}{*}{ PRT } & Rendah & {$[0,10)$} & Linear Turun \\
\hline & Sedang & $(0,20)$ & Segitiga \\
\hline & Tinggi & $(10,100]$ & Bahu Kanan \\
\hline \multirow{3}{*}{ AFU } & Rendah & {$[0,4)$} & Linear Turun \\
\hline & Sedang & $(0,7)$ & Segitiga \\
\hline & Tinggi & $(4,10]$ & Bahu Kanan \\
\hline \multirow{2}{*}{ SD } & $\begin{array}{l}\text { Desa } \\
\text { Perdesaan }\end{array}$ & {$[0,15)$} & Bahu Kiri \\
\hline & $\begin{array}{l}\text { Desa } \\
\text { Perkotaan }\end{array}$ & $(5,20]$ & Bahu Kanan \\
\hline
\end{tabular}

Berdasarkan Tabel 1, fungsi keanggotaan dari masing-masing variabel direpresentasikan sebagai berikut.

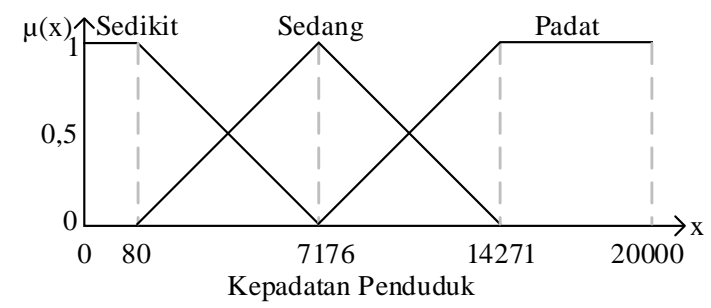

Gambar 1. Fungsi Keanggotaan Variabel Kepadatan Penduduk

Fungsi keanggotaan variabel kepadatan penduduk:

$$
\begin{aligned}
& \mu_{\text {Sedikit }}(x)=\left\{\begin{array}{c}
1, x<80 ; \\
\frac{7176-x}{7096}, 80 \leq x \leq 7176 ; \\
0, x>7176 .
\end{array}\right. \\
& \mu_{\text {Sedang }}(x)=\left\{\begin{array}{c}
\frac{x-80}{7096}, 80 \leq x<7176 ; \\
\frac{14271-x}{7095}, 7176 \leq x \leq 14271 ; \\
0, x>14271 \text { atau } x<80 .
\end{array}\right.
\end{aligned}
$$

$\mu_{\text {Padat }}(x)=\left\{\begin{array}{c}0, x<7176 ; \\ \frac{x-7176}{7095}, 7176 \leq x \leq 14271 ; \\ 1, x>14271 .\end{array}\right.$

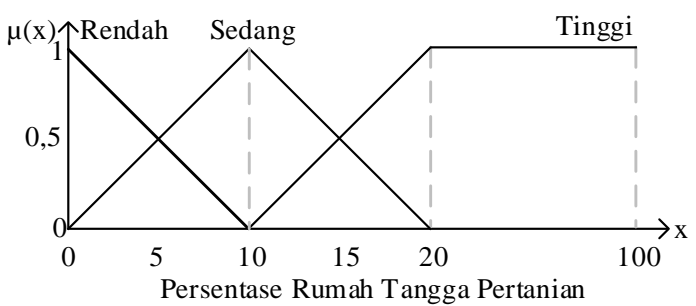

Gambar 2. Fungsi Keanggotaan Variabel Persentase Rumah Tangga Pertanian

Fungsi keanggotaan variabel persentase rumah tangga pertanian:

$\mu_{\text {Rendah }}(x)=\left\{\begin{array}{c}1, x<0 \\ \frac{10-x}{10}, 0 \leq x \leq 10 \\ 0, x>10\end{array}\right.$

$\mu_{\text {Sedang }}(x)=\left\{\begin{array}{l}0, x<0 \text { atau } x>20 \\ \frac{x-0}{10}, 0 \leq x<10 \\ \frac{20-x}{10}, 10 \leq x \leq 20\end{array}\right.$

$\mu_{\text {Tinggi }}(x)=\left\{\begin{array}{c}0, x<10 ; \\ \frac{x-10}{10}, 10 \leq x \leq 20 ; \\ 1, x>20 .\end{array}\right.$ 


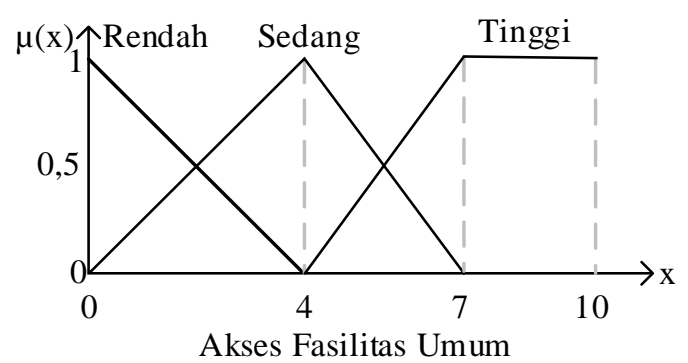

Gambar 3. Fungsi Keanggotaan Variabel Akses Fasilitas Umum

Fungsi keanggotaan variabel akses fasilitas umum:

$$
\begin{aligned}
& \mu_{\text {Rendah }}(x)=\left\{\begin{array}{c}
1, x<0 ; \\
\frac{4-x}{4}, 0 \leq x \leq 4 ; \\
0, x>4 .
\end{array}\right. \\
& \mu_{\text {Sedang }}(x)=\left\{\begin{array}{c}
0, x<0 \text { atau } x>7 ; \\
\frac{x-0}{4}, 0 \leq x<4 ;
\end{array}\right. \\
& \mu_{\text {Tinggi }}(x)=\left\{\begin{array}{c}
\frac{7-x}{3}, 4 \leq x \leq 7 . \\
\frac{x-4}{3}, 4 \leq x \leq 7 ; \\
1, x>7 .
\end{array}\right.
\end{aligned}
$$

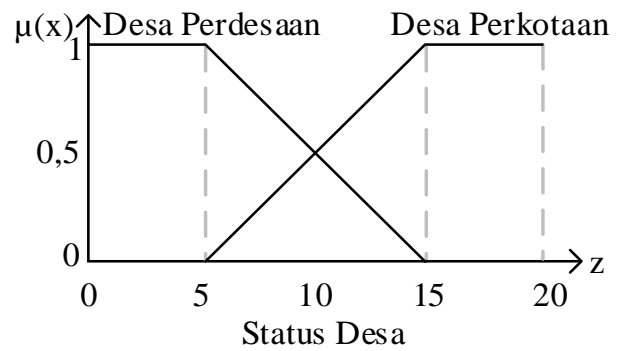

Gambar 4. Fungsi Keanggotaan Variabel Status Desa

Fungsi keanggotaan variabel status desa:

$$
\begin{gathered}
\mu_{\text {Desa Perdesaan }}(z)=\left\{\begin{array}{c}
1, z<5 ; \\
\frac{15-z}{10}, 5 \leq z \leq 15 ; \\
0, z>15 .
\end{array}\right. \\
\mu_{\text {Desa Perkotaan }}(z)=\left\{\begin{array}{c}
0, z<5 ; \\
\frac{z-5}{10}, 5 \leq z \leq 15 ; \\
1, z>15 .
\end{array}\right.
\end{gathered}
$$

\section{Menentukan Aturan Fuzzy}

Banyak aturan fuzzy yang terbentuk dari tiga variabel input dengan masing-masing tiga himpunan fuzzy adalah $3^{3}=27$ aturan fuzzy.
Tabel 2. Aturan Fuzzy

\begin{tabular}{|l|l|l|l|l|}
\hline R & KPD & PRT & AFU & SD \\
\hline 1 & Sedikit & Sedang & Rendah & Desa Perdesaan \\
\hline 2 & Sedikit & Tinggi & Rendah & Desa Perdesaan \\
\hline 3 & Sedang & Tinggi & Rendah & Desa Perdesaan \\
\hline 4 & Padat & Tinggi & Rendah & Desa Perdesaan \\
\hline 5 & Sedikit & Rendah & Rendah & Desa Perkotaan \\
\hline 6 & Sedikit & Rendah & Sedang & Desa Perkotaan \\
\hline 7 & Sedikit & Rendah & Tinggi & Desa Perkotaan \\
\hline 8 & Sedikit & Sedang & Sedang & Desa Perkotaan \\
\hline 9 & Sedikit & Sedang & Tinggi & Desa Perkotaan \\
\hline 10 & Sedikit & Tinggi & Sedang & Desa Perkotaan \\
\hline 11 & Sedikit & Tinggi & Tinggi & Desa Perkotaan \\
\hline 12 & Sedang & Rendah & Rendah & Desa Perkotaan \\
\hline 13 & Sedang & Rendah & Sedang & Desa Perkotaan \\
\hline 14 & Sedang & Rendah & Tinggi & Desa Perkotaan \\
\hline 15 & Sedang & Sedang & Rendah & Desa Perkotaan \\
\hline 16 & Sedang & Sedang & Sedang & Desa Perkotaan \\
\hline 17 & Sedang & Sedang & Tinggi & Desa Perkotaan \\
\hline 18 & Sedang & Tinggi & Sedang & Desa Perkotaan \\
\hline 19 & Sedang & Tinggi & Tinggi & Desa Perkotaan \\
\hline 20 & Padat & Rendah & Rendah & Desa Perkotaan \\
\hline 21 & Padat & Rendah & Sedang & Desa Perkotaan \\
\hline 22 & Padat & Rendah & Tinggi & Desa Perkotaan \\
\hline 23 & Padat & Sedang & Rendah & Desa Perkotaan \\
\hline 24 & Padat & Sedang & Sedang & Desa Perkotaan \\
\hline 25 & Padat & Sedang & Tinggi & Desa Perkotaan \\
\hline 26 & Padat & Tinggi & Sedang & Desa Perkotaan \\
\hline 27 & Padat & Tinggi & Tinggi & Desa Perkotaan \\
\hline & & & & \\
\hline
\end{tabular}

\section{Aplikasi Fungsi Implikasi Min}

Fungsi implikasi yang akan digunakan adalah fungsi implikasi min yaitu dengan mengambil nilai keanggotaan terkecil untuk setiap aturan fuzzy. Misalkan diambil data desa 1 yaitu Desa Sakti dalam Tabel 3.

Tabel 3. Data Desa 1

\begin{tabular}{|l|l|}
\hline Variabel & Data Desa 1 \\
\hline KPD & 250,23 \\
\hline PRT & 8,84 \\
\hline AFU & 1 \\
\hline SD & Desa Perdesaan \\
\hline
\end{tabular}

Selanjutnya data pada Tabel 3 diubah dalam himpunan fuzzy dengan mencari derajat keanggotaan menggunakan fungsi pendekatan masing-masing himpunan yang disajikan dalam Tabel 4. 
Tabel 4. Derajat Keanggotaan Desa 1

\begin{tabular}{|l|l|l|}
\hline $\begin{array}{l}\text { Variabel } \\
\text { Input }\end{array}$ & $\begin{array}{l}\text { Himpunan } \\
\text { Fuzzy }\end{array}$ & $\begin{array}{l}\text { Derajat } \\
\text { Keanggotaan }\end{array}$ \\
\hline \multirow{4}{*}{ KPD } & Sedikit & 0,98 \\
\cline { 2 - 3 } & Sedang & 0,02 \\
\cline { 2 - 3 } & Padat & 0 \\
\hline \multirow{4}{*}{ PRT } & Rendah & 0,12 \\
\cline { 2 - 3 } & Sedang & 0,88 \\
\cline { 2 - 3 } & Tinggi & 0 \\
\hline \multirow{4}{*}{ AFU } & Rendah & 0,75 \\
\cline { 2 - 3 } & Sedang & 0,25 \\
\cline { 2 - 3 } & Tinggi & 0 \\
\hline
\end{tabular}

Selanjutnya dilakukan operasi komposisi pada setiap rule, derajat keanggotaan hasil operasi komposisi kemudian digunakan untuk melakukan implikasi min untuk memperoleh solusi setiap rule. Hasil operasi komposisi desa 1 untuk rule 1 sampai rule 27 :

$\alpha_{1}=\min (0,98 ; 0,88 ; 0,75)=0,75$

$\alpha_{2}=\min (0,98 ; 0 ; 0,75)=0$;

$\alpha_{3}=\min (0,02 ; 0 ; 0,75)=0$;

$\alpha_{27}=\min (0 ; 0 ; 0)=0$.

Berdasarkan hasil operasi komposisi di atas, maka fungsi implikasi min desa 1 untuk rule 1 sampai rule 27 sebagai berikut:

$$
\begin{aligned}
\mu_{R 1}(z) & =\alpha_{1} \wedge \mu_{\text {Desa Perdesaan }}(z) \\
& =\min \left(0,75, \mu_{\text {Desa Perdesaan }}(z)\right) ; \\
\mu_{R 2}(z)= & \alpha_{2} \wedge \mu_{\text {Desa Perdesaan }}(z) \\
= & \min \left(0, \mu_{\text {Desa Perdesaan }}(z)\right) ; \\
\mu_{R 3}(z)= & \alpha_{3} \wedge \mu_{\text {Desa Perdesaan }}(z) \\
= & \min \left(0, \mu_{\text {Desa Perdesaan }}(z)\right) ; \\
& \vdots \\
\mu_{R 27}(z)= & \alpha_{27} \wedge \mu_{\text {Desa Perkotaan }}(z) \\
= & \min \left(0, \mu_{\text {Desa Perkotaan }}(z)\right)
\end{aligned}
$$

Sehingga diperoleh fungsi keanggotaan hasil implikasi min untuk setiap rule pada desa 1 yang disajikan pada Tabel 5.

Berdasarkan fungsi implikasi pada Tabel 5 diketahui bahwa dari 27 rule pada desa 1 yang memiliki daerah hasil implikasi selain 0 yaitu rule: $1,5,6,8,12,13,15$, dan 16 .
Tabel 5. Fungsi Keanggotaan Hasil Implikasi Min Desa 1

\begin{tabular}{|c|c|}
\hline $\mathrm{R}$ & Fungsi Keanggotaan \\
\hline 1 & $\mu_{R 1}(z)=\left\{\begin{array}{c}0, z<7,5 ; \\
\frac{15-z}{10}, 7,5 \leq z \leq 15 ; \\
0, z>15 .\end{array}\right.$ \\
\hline 2 & $\mu_{R 2}(z)=\{0, \forall z \in R 2$. \\
\hline 3 & $\mu_{R 3}(z)=\{0, \forall z \in R 3$. \\
\hline$\vdots$ & $\vdots$ \\
\hline 27 & $\mu_{R 27}(z)=\{0, \forall z \in R 27$. \\
\hline
\end{tabular}

Gambar 5 berikut merupakan daerah hasil implikasi desa 1 untuk rule 1.

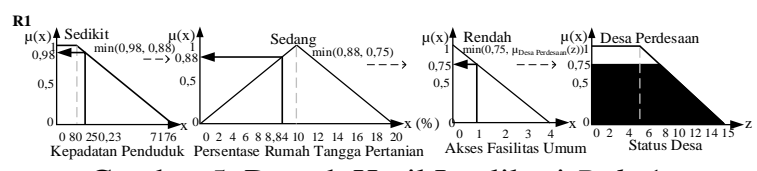

Gambar 5. Daerah Hasil Implikasi Rule 1

\section{Melakukan Agregasi}

Solusi himpunan fuzzy diperoleh dengan cara mengambil nilai maksimum output aturan hasil aplikasi fungsi implikasi min, kemudian menggunakannya untuk memodifikasi daerah fuzzy, dan mengaplikasikannya ke output dengan menggunakan operator OR (union). Hasil komposisi aturan max untuk setiap himpunan fuzzy variabel output sebagai berikut:

$$
\begin{aligned}
& \mu_{\text {Desa Perdesaan }}(z) \\
& =\max \left\{\mu_{R 1}(z), \mu_{R 2}(z), \mu_{R 3}(z), \mu_{R 4}(z)\right\} \\
& =\mu_{R 1}(z) \\
& \mu_{\text {Desa Perkotaan }}(z) \\
& =\max \left\{\mu_{R 5}(z), \mu_{R 6}(z), \mu_{R 7}(z), \ldots, \mu_{R 27}(z)\right\} \\
& =\mu_{R 8}(z)
\end{aligned}
$$

Pada persamaan di atas diketahui bahwa fungsi maksimum untuk output desa perdesaan adalah rule 1 dan fungsi maksimum untuk output desa perkotaan adalah rule 8 , yang telah mewakili nilai pada masing-masing himpunan fuzzy variabel output hasil implikasi setiap rule. Persamaan agregasi untuk desa 1 sebagai berikut:

$$
\begin{aligned}
& \mu_{s f}(z) \\
& =\max \left\{\mu_{\text {Desa Perdesaan }}(z), \mu_{\text {Desa Perkotaan }}(z)\right\} \\
& =\max \left\{\mu_{R 1}(z), \mu_{R 8}(z)\right\}
\end{aligned}
$$


Daerah hasil agregasi desa 1 dapat dilihat pada gambar berikut:

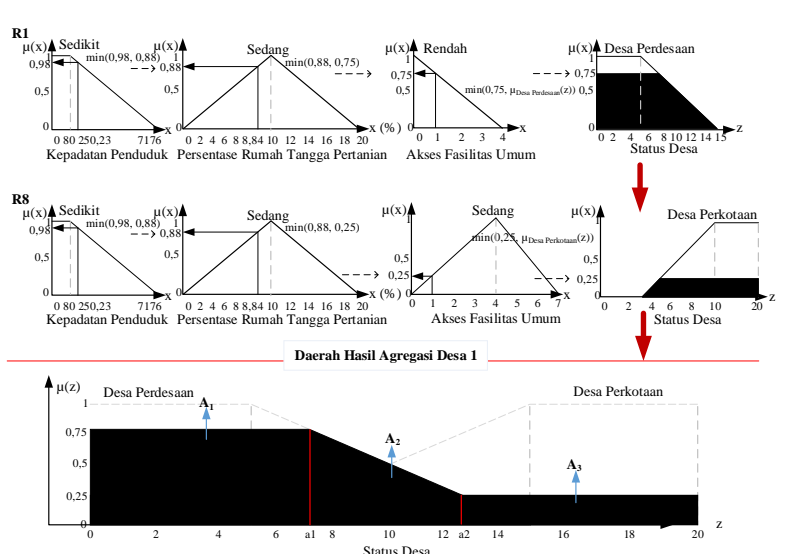

Gambar 6. Daerah Hasil Agregasi Desa 1

Fungsi keanggotaan hasil agregasi desa 1 adalah sebagai berikut:

$$
\mu_{s f}(z)=\left\{\begin{array}{c}
0,75 ; 0 \leq z<7,5 \\
\frac{15-z}{10} ; 7,5 \leq z<12,5 \\
0,25 ; 12,5 \leq z \leq 20
\end{array}\right.
$$

\section{Melakukan Defuzzifikasi}

Pertama hitung momen untuk setiap daerah sebagai berikut:

$$
\begin{aligned}
M_{1} & \left.=\int_{0}^{7,5}(0,75) z d z=0,375 z^{2}\right]_{0}^{7,5} \\
& =21,09375 ; \\
M_{2} & =\int_{7,5}^{12,5}\left(\frac{15-z}{10}\right) z d z
\end{aligned}
$$

$$
\begin{aligned}
& =\frac{1}{10}\left[7,5 z^{2}-\frac{z^{3}}{3}\right]_{7,5}^{12,5}=23,958 \\
M_{3} & \left.=\int_{12,5}^{20}(0,25) z d z=0,125 z^{2}\right]_{12,5}^{20} \\
& =30,46875
\end{aligned}
$$

Kemudian hitung luas setiap daerah hasil agregasi desa 1 sebagai berikut:

$$
\begin{aligned}
A_{1} & \left.=\int_{0}^{7,5} 0,75 d z=0,75 z\right]_{0}^{7,5}=5,625 \\
A_{2} & =\int_{7,5}^{12,5}\left(\frac{15-z}{10}\right) d z=\frac{1}{10}\left[15 z-\frac{z^{2}}{2}\right]_{7,5}^{12,5} \\
& =2,5 ; \\
A_{3} & \left.=\int_{12,5}^{20} 0,25 d z=0,25 z\right]_{12,5}^{20}=1,875
\end{aligned}
$$

Sehingga diperoleh hasil defuzzifikasi sebagai berikut:

$$
\begin{aligned}
z^{*} & =\frac{21,09375+23,958+30,46875}{5,625+2,5+1,875} \\
& =\frac{75,5205}{10}=7,55205 \approx 7,6
\end{aligned}
$$

Jadi nilai defuzzifikasi untuk desa 1 adalah 7,6.

\section{Hasil Klasifikasi Setiap Desa}

Hasil klasifikasi untuk desa 1 sampai desa 59 dapat dilihat pada Tabel 6 berikut.

Tabel 6. Hasil Klasifikasi Setiap Desa

\begin{tabular}{|c|l|c|c|c|c|c|c|}
\hline \multirow{2}{*}{ No } & \multirow{2}{*}{ Nama Desa } & \multirow{2}{*}{$\begin{array}{c}\text { Total } \\
\text { Score }\end{array}$} & \multirow{2}{*}{$z^{*}$} & \multicolumn{2}{|c|}{$\mu\left(z^{*}\right)$} & \multicolumn{2}{c|}{ Status Desa } \\
\cline { 5 - 8 } & & & $\begin{array}{c}\text { Desa } \\
\text { Perdesaan }\end{array}$ & $\begin{array}{c}\text { Desa } \\
\text { Perkotaan }\end{array}$ & Prediksi & Asli \\
\hline 1 & Sakti & 9 & 7,6 & 0,74 & 0,26 & Desa Perdesaan & Desa Perdesaan \\
\hline 2 & Bunga Mekar & 10 & 10 & 0,5 & 0,5 & Desa Perkotaan & Desa Perkotaan \\
\hline 3 & Batumadeg & 10 & 10,1 & 0,49 & 0,51 & Desa Perkotaan & Desa Perkotaan \\
\hline 4 & Klumpu & 11 & 12,5 & 0,25 & 0,75 & Desa Perkotaan & Desa Perkotaan \\
\hline 5 & Batukandik & 10 & 10 & 0,5 & 0,5 & Desa Perkotaan & Desa Perkotaan \\
\hline 6 & Sekartaji & 10 & 11,2 & 0,38 & 0,62 & Desa Perkotaan & Desa Perkotaan \\
\hline 7 & Tanglad & 11 & 11,8 & 0,32 & 0,68 & Desa Perkotaan & Desa Perkotaan \\
\hline 8 & Pejukutan & 10 & 10 & 0,5 & 0,5 & Desa Perkotaan & Desa Perkotaan \\
\hline$\vdots$ & $\vdots$ & $\vdots$ & $\vdots$ & $\vdots$ & $\vdots$ & $\vdots$ & $\vdots$ \\
\hline 59 & Besan & 8 & 7,53 & 0,747 & 0,253 & Desa Perdesaan & Desa Perdesaan \\
\hline
\end{tabular}


Hasil klasifikasi untuk setiap desa diperoleh dengan mensubstitusikan nilai defuzzifikasinya ke dalam fungsi keanggotaan pada masingmasing himpunan fuzzy variabel output dan menentukan klasifikasi dengan nilai yang diperoleh. Pada Tabel 7 baris pertama yaitu desa 1 (Desa Sakti) dapat dilihat derajat keanggotaan $\mu\left(z^{*}\right)$ desa perdesaan lebih besar daripada desa perkotaan yaitu 0,74 maka desa 1 terklasifikasi sebagai desa perdesaan. Penentuan status desa untuk desa dua sampai desa 59 juga sama seperti desa 1.

\section{Uji Ketepatan Hasil Klasifikasi}

Pengujian dilakukan dengan membandingkan keluaran metode Mamdani dengan data asli. Hasil pengujian disajikan pada Tabel 7.

Tabel 7. Confusion Matrix

\begin{tabular}{|c|c|c|c|}
\hline \multirow{2}{*}{$\begin{array}{c}\text { Hasil } \\
\text { Observasi } \\
\text { (actual } \\
\text { class) }\end{array}$} & \multicolumn{2}{|c|}{$\begin{array}{c}\text { Hasil Prediksi } \\
\text { (predicted class) }\end{array}$} & \multirow{2}{*}{ Jumlah } \\
\cline { 2 - 3 } & $\begin{array}{c}\text { Desa } \\
\text { Perdesaan }\end{array}$ & $\begin{array}{c}\text { Desa } \\
\text { Perkotaan }\end{array}$ & \\
\hline $\begin{array}{c}\text { Desa } \\
\text { Perdesaan }\end{array}$ & 4 & 1 & 5 \\
\hline $\begin{array}{c}\text { Desa } \\
\text { Perkotaan }\end{array}$ & 3 & 51 & 54 \\
\hline Jumlah & 7 & 52 & 59 \\
\hline
\end{tabular}

Banyaknya hasil prediksi klasifikasi desa yang sesuai adalah 55 desa, banyaknya prediksi desa dengan status desa perdesaan sedangkan klasifikasi asli yaitu desa perkotaan adalah 3 desa. Banyaknya prediksi desa dengan status desa perkotaan sedangkan klasifikasi asli yaitu desa perdesaan adalah 1 desa dengan jumlah seluruh desa yaitu 59 desa.

Uji ketepatan/ akurasi hasil klasifikasi dapat dihitung dengan rumus berikut :

$$
\begin{gathered}
\text { Akurasi }=\frac{4+51}{4+1+3+51}=\frac{55}{59}=0,93 \\
=93 \%
\end{gathered}
$$

\section{KESIMPULAN DAN SARAN}

\section{A. KESIMPULAN}

Berdasarkan hasil pengolahan data dalam mengklasifikasikan desa perkotaan dan desa perdesaan di Kabupaten Klungkung diperoleh kesimpulan sebagai berikut:

1. Metode Mamdani dapat digunakan dalam mengklasifikasikan desa di Kabupaten Klungkung. Hasil klasifikasi dengan metode Mamdani menghasilkan 52 desa terklasifikasi menjadi desa perkotaan dan tujuh desa menjadi desa perdesaan dengan tingkat akurasi sebesar 93\% antara keluaran metode Mamdani dengan data asli pada 59 desa di Kabupaten Klungkung.

2. Terdapat perbedaan pada total skor dan status desa antara keluaran metode Mamdani dengan data asli. Dari 59 desa ada empat desa yang terklasifikasi berbeda dengan status desa aslinya yaitu desa: Getakan, Jumpai, Selisihan, dan Pesinggahan.

\section{B. SARAN}

Adapun saran yang dapat diberikan pada penelitian tentang klasifikasi desa perkotaan dan desa perdesaan selanjutnya yaitu:

1. Menggunakan metode model fuzzy yang lain seperti metode Tsukamoto dan metode Sugeno.

2. Menggunakan variabel tambahan yang lain seperti ketersediaan internet, sehingga diperoleh hasil klasifikasi yang lebih baik.

\section{DAFTAR PUSTAKA}

Arifin, S., Muslim, M. A., \& Sugiman. (2015). Implementasi Logika Fuzzy Mamdani untuk Mendeteksi Kerentanan Daerah Banjir di Semarang Utara. Scientific Journal of Informatics Vol. 2, No. 2, November 2015, 179-192.

Ayuningtiyas, I. K., Saptono, F., \& Hidayat, T. (2007). Sistem Pendukung Keputusan Penanganan Kesehatan Balita Menggunakan Penalaran Fuzzy Mamdani. Seminar Nasional Aplikasi Teknologi Informasi 2007 (SNATI 207), L-65-L71. 
Badan Pusat Statistik. (2010). Klasifikasi Perkotaan dan Perdesaan di Indonesia. Jakarta: Badan Pusat Statistik.

Badan Pusat Statistik Kabupaten Klungkung. (2016). Kabupaten Klungkung Dalam Angka. Klungkung: Badan Pusat Statistik Kabupaten Klungkung.

Bojadziev, G., \& Bojadziev, M. (2007). Fuzzy Logic for Business, Finance, and Management. Singapore: World Scientific Publishing Co. Pte. Ltd.

Kusumadewi, S., \& Purnomo, H. (2010). Aplikasi Logika Fuzzy untuk Pendukung Keputusan. Yogyakarta: Graha Ilmu.

Muthohar, A., \& Rahayu , Y. (2016). Implementasi Logika Fuzzy Mamdani pada Penilaian Kinerja Pelayanan Perawat. Journal of Applied Intelligent System, Vol.1, No. 1, 67-76. 